\title{
AN OPTIMIZATION MODEL FOR PRECAST PROJECT PLANNING USING GROUP CONCEPTS
}

\author{
Kuo-Chuan Shih \\ National Chengchi University
}

\author{
Shu-Shun Liu \\ National Yunlin University of Science and Technology
}

(Received June 15, 2009; Revised June 18, 2010)

\begin{abstract}
Construction projects adopting precast pieces are feasible to reduce project uncertainties over components which are produced in factories, stored in factories or external sites, and transported with trucks to satisfy installation demand. In order to create project plans, planners should arrange available resources and select appropriate ways to produce, store, and transport components. This study adopts several group ideas to organize an overall precast project. Based on these group concepts, an optimization model and a recursive procedure are proposed. Appropriate molds and zones can be determined in the recursive procedure, and the project plan can be created through the optimized project cost. An example experiment is demonstrated to explain the feasibility of the proposed model and group concepts.
\end{abstract}

Keywords: Project planning, precast project, construction, optimization, group

\section{Introduction}

Construction projects are sensitive while underway. Uncertainties such as weather-related factors have influence on both project schedule and quality. In order to eliminate from uncertainties, the precast method is a construction method with its industrial characteristics being closest to those of the manufacture industry. Nowadays, the precast method has been successfully applied in projects of constructing bridges, factories, tunnels, and various buildings. Precast projects are common in the construction industry.

The whole process of precast projects can be divided into 5 stages: design, production, storage, transportation, and installation. Furthermore, at least 4 roles: client, architect, contractor, and precast factory, are involved. Nevertheless, the precast factory is always the hinge of projects. From the perspective of the precast factory, the design stage and the installation stage may be out of control. In the design stage, the architect confirms details including shape, strength, and material(s) for all components with the client to make component information exact. Then, the precast factory produces components according to the confirmed component information. Later, the contractor installs components in the installation stage. The precast factory supplies the contractor components in the right sequence, on time. Therefore, the precast factory is always charged to plan in the domain of the production stage, the storage stage, and the transportation stage of precast projects.

There are dilemmas when creating precast project plans. For example, high production of components produced with high operating costs may accompany shortages of resources and insufficiency of storage space. Contrarily, low productivity may idle resources and storage space. Additionally, there are various ways to produce and store components. Planners must utilize available resources in appropriate ways. Thus, this study proposes a solution for these planning issues. 


\section{Lecture Review}

Precast related studies can be classified to two types: techniques and planning. Precast techniques can mainly refer to the annual International Symposium on Automation and Robotics in Construction (ISARC) conference. Novel techniques or machines are continually innovated and developed. These techniques or machines not only provide chances to enhance ability of precast works, but change behavior in producing, storing, and transporting precast components. Therefore, precast planning involves changeable work environment according to technique issues. Only a few studies on precast planning have been investigated.

Planning issues of the production stage have been studied for years. Chan has conducted several studies in production planning. In order to cater to different degrees of component standardization, Chan and $\mathrm{Hu}[3]$ proposed two models: (1) the comprehensive method utilizes resources regularly to produce components; (2) the specialized method considers low component standardization. Furthermore, Chan and $\mathrm{Hu}$ [4] proposed a Constraint Programming based optimization model to compare regular rules of component production. Components and molds were grouped into component types and mold types. Chan and Zeng [5] and Chan and Zeng [6] proposed a coordinated production scheduling and rescheduling model respectively. Chan and $\mathrm{Lu} \mathrm{[7]}$ adopted simulation to build scenarios of viaduct production for analysis. Both supply-demand matching and high productivity were under consideration. Others, such as Leu and Hwang [9] have proposed a GA-based scheduling model considering the resource-constrained environment. The importance of manpower, cranes, steam curing capacity, and storage space of reinforcement cages are issues.

Investigations of storage-transportation planning have seldom been made. One of the reasons is the huge components. Containerization has a similar issue that definitely should be explored. Vis and Koster [12] discussed the process of transporting containers from ships to a terminal. Avriel et al. [2] proposed a mathematical model to reduce the number of times a container is moved. However, various shapes of components are reasons why few investigations are made. Sadiq et al. [10] proposed a cluster-analysis base model to classify objects into several groups, then allocating groups to store objects. Shih et al. [11] proposed component zoning, such that components are grouped into zones to create storagetransportation plans. Furthermore, inventory and transportation are related to time-base and quantity-base issues as Cetinkaya et al. [8] mentioned. The Acheson and Glover Group [1] developed a precast storage system. Storing precast components with few secondary movements and well-located components was considered.

Based on responsibility of precast factory, production, storage, and transportation stages are essential to concern. To handle changeable work environment caused by novel techniques, precast plans must contain flexibility to keep them practical. Adopting group concepts provides a solution to precast project planning.

\section{Framework Explanation}

The quantity of components for a construction precast project can be hundreds or even thousands. Grouping components is necessary in precast projects. In practice, components are standardized into groups for at least three advantages: (1) components can be unified, and work can be simplified; (2) high production efficiency can be achieved, and resources can be utilized repeatedly; (3) components can be reciprocal substitutes. As a natural assumption of precast projects, a high degree of component standardization is required, or the precast method may be unsuitable.

Before planning a project from the perspective of the precast factory, component infor- 


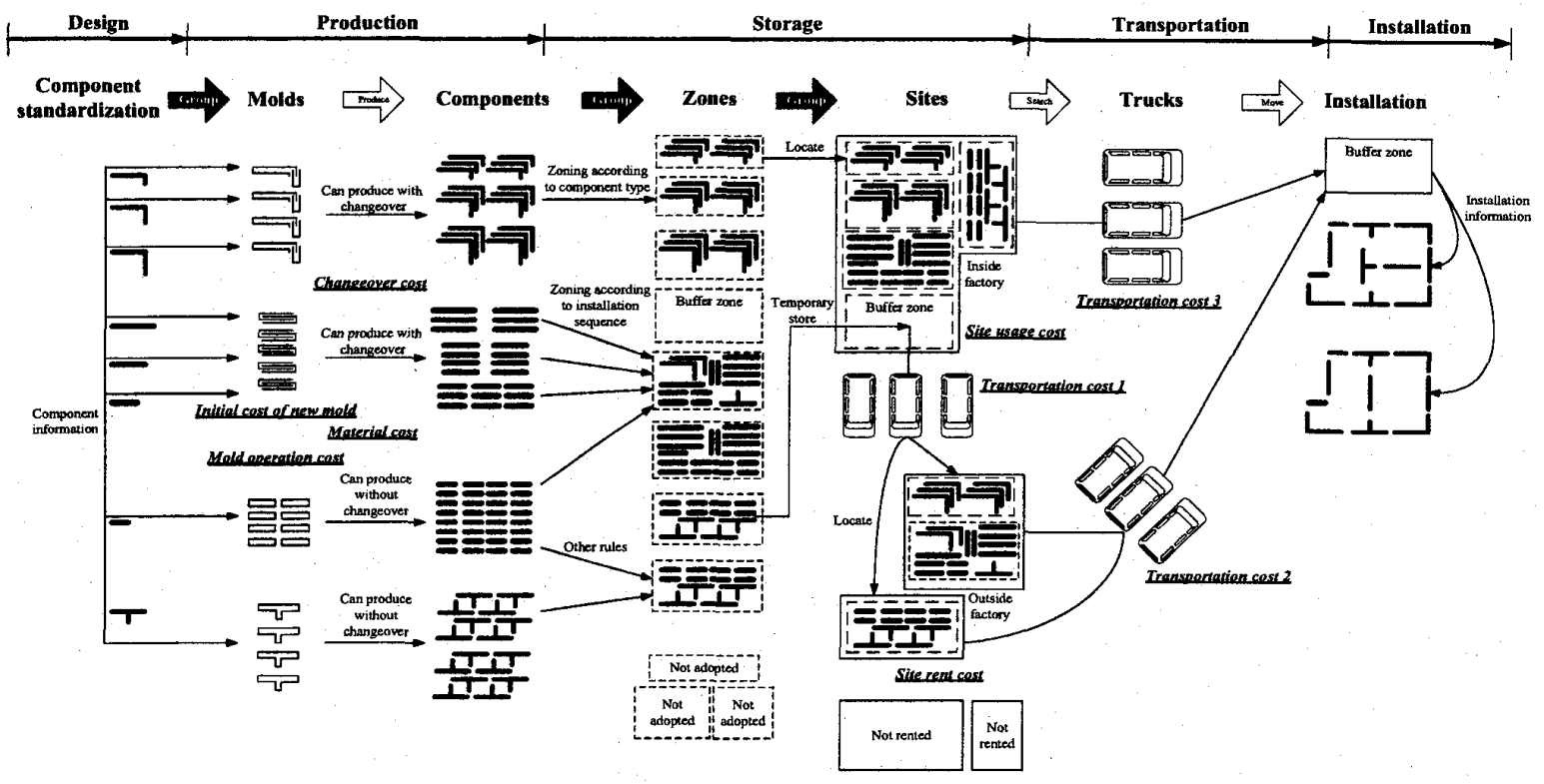

Figure 1: Overall process of precast projects

mation and installation information are required as stipulations in a contract. First, the components of the project are grouped into component types according to standardized shapes, strengths, and materials based on the architect's design. Numbers of component types and ways to produce components are recognized. Next, component requirements are scheduled as installation information. The installation information indicates when and how many components of each component type are required. Based on the known component information and installation information, the precast factory arranges resources to produce, store, and transport components under the contract. The overall process of precast projects is represented as Figure 1.

\subsection{Group concepts}

Group concepts are further explained as follows:

Mold type: Based on the component information, ways to produce components are recognized. Components within a component type can be produced with the same molds, materials, manpower, machines, and production procedures. Production work can be unified in most factories. Steel molds with high initial cost are usual to produce components smoothly and to utilize molds repeatedly. Furthermore, molds are always used to produce component types of given shapes. Thus, utilization of molds becomes the key issue.

To clearly identify the concepts of component type and mold type, components within a component type are reciprocal and identical with shape, strength, and materials. Components belonging to a specific component type can be produced with the same resources and production processes. Therefore, a mold can produce components within a component type. Moreover, molds herein can be adjusted to produce components belonging to grouped component types. Mold changeover occurs when molds produce different components of the grouped component types. Molds are grouped into a mold type if they have the same ability to produce corresponding grouped component types.

A production plan can be represented as a schedule of mold utilization for all molds. Planners organize molds to produce required components. Resources in factories are in harmony with the molds. However, several issues are concerned: (1) what type and how many molds are required; (2) efficiency and economy of mold utilization; (3) how to identify 
and avoid mold changeovers; (4) other resource limitations of factories.

Component zoning and zone type: Construction components are complex and difficult to store because they are huge and have various shapes. Storing construction components is regarded as 2-dimensional or 3-dimensional spatial allocation problems with loading consideration. Ways and rules to storing components often depend on experience.

Concepts of cluster-analysis offer a solution to simplify storage issues by grouping components. Components are grouped into zones in this study. A zone is a suppositional space where components can be gathered by following specific rules assigned by planners. As an example of goods packing, there are various boxes for goods. Each box has its rules such as height, width, and strength limitations to pack goods. If the goods are recognized, packers should choose appropriate boxes to store goods. After goods are packed, boxes become bases in the process of goods storage. In a situation similar to components and zones, zones are bases in the storage stage instead of components. However, rules of zones are required to group components.

There are too many considerations or rules for storing components. To simplify the complexity of component zoning, three parameters are adopted as rules for zones: (1) required storage space; (2) component types that can be stored there; (3) allowed component quantity for each component type. Additionally, zones can belong to a zone type if they are formulated with equivalent parameters. Before formulating zone types, two assumptions are made as follows: first, parameters of each zone type are verified based on overall environmental considerations including weather, available equipment, interior or outdoor storage, limitation of vertical loading, safe distance between components, and assorted ways to store components. Experts or performers in component storage should be involved to formulate zone types. Next, various zone types are encouraged. A zone type presents a way to store corresponding components. However, planners cannot assure that a zone type can accommodate all projects. If various zone types are available, planners can choose appropriate ways to store components for each individual project.

How zones are formulated are key issues but is outside the realm of this study since the problem is complex and case by case. Therefore, zone types with their parameters are assumed to be available for planners in this study.

Zone locating: Extending concepts of component zoning, adopted zones are located in sites, which are units of real storage space, to store components. In practice, precast factories often have their own internal sites with movement equipment to store components conveniently. Adopted zones can be located in the factory. Moreover external sites can be choices when internal site space is not enough.

Locating zones determines which sites zones store components in. In other words, zones are grouped in sites to store components. The relationships between zones and sites concern storage space. Zones can be located in either internal sites or external sites. If zones are located in external sites, external sites have to be rented, and additional component transportation is needed. Moreover, components are produced and initially stored in the factory. Components of those zones in external sites are temporarily stored in zones in internal sites after component production, and then transported from the zones in internal sites to those zones in external sites. Buffer zones in external sites may be required to temporarily store components.

The storage plan of a precast project can be represented as a problem of component zoning and zone locating as shown in Figure 1. Planners choose appropriate zones and arrange sites they own to store components. However, several issues are concerned: (1) which and how many zones are appropriate; (2) utilization of internal sites; (3) necessity 
and economy of external sites.

\subsection{Transportation:}

Two kinds of component transportation are recognized: (1) movement within a site; (2) long distance transportation between two sites. Component movement within a site means that components are moved within the factory, a site, or the work site. Equipments such as cranes and trams are available. Such equipments can be owned or rented for the daily business of the factory. Hence, the component movement cost in this case can be assigned to a particular project or transformed into the cost of factory operation or site setting cost. Moreover, long distance component transportation is performed by trucks. In practice, trucks are mostly rented case by case. Two factors: weight of components and distance transported are commonly considered for truck rental fee calculation. Such transportation behavior is considered herein.

\section{Mathematical Model and Optimization}

An overview of precast project planning can be organized by combining proposed concepts of group and the mentioned transportation issues as shown as Figure 1.

\subsection{Assumptions}

To build a specific context of precast project planning, further assumptions and descriptions are made as follows:

- Perspective: a project plan including production, storage, and transportation stages for a precast factory is considered. The factory has production resources, its own internal sites, and available external sites.

- Mold: each mold can daily produce only a component. Mold changeover and component producing can be completed within one day.

- Production limitation: most resources are unlimited. However, limitation of daily use of concrete and limitation of production space in the factory are concerned because they are common factors to restrain productivity.

- Site: internal sites are in the factory. External sites are located in a neighbourhood outside the factory. Thus, distances between the factory and external sites are unified. Costs of internal sites or rental costs of external sites are involved in daily cost calculations to determine site adoptions.

- Standardized space: 2-dimensional or 3-dimensional spaces that include production space, factory, zones, and sites are rectangular or with standardized rules. Thus, spatial relationships both adapting molds to production space and located zones to sites are feasible.

- Transportation: only three types of transportation are allowed: (1) zones in internal sites to those in external sites; (2) zones in internal sites to the work site; (3) zones in external sites to the work site. Moreover, components can not be transported unless a minimal quantity is met to order trucks. At least eighteen tons is measured to make an order herein. Additionally, components cannot be transported before their curing is complete. Thus, components must be stored in zones in internal sites for two days.

- Only workdays are planned.

\subsection{Model}

A mathematical model integrating the mentioned issues is built as follows. Symbols refer to Table 1 and Table 2:

- Objective function: 


$$
\text { Minimize } T M+T S p M+T S e M+I C+T C
$$

where

$$
\begin{gathered}
T M=\sum_{i=1}^{n m} U M_{i} \times i c m_{i} \\
T S p M=\sum_{k=1}^{p e r i o d} P S_{k} \times p o c \\
T S e M=\sum_{i=1}^{n m} \sum_{k=0}^{p e r i o d} S C M_{i, k} \times s c m \\
I C=\sum_{m=1}^{n i} \sum_{k=0}^{p e r i o d} U I_{m, k} \times i c_{m}+\sum_{n=1}^{n e} \sum_{k=1}^{p e r i o d} U E_{n, k} \times e c_{n} \\
T C=\left[\sum_{o=1}^{n z} \sum_{p=1}^{n z} \sum_{j=1}^{n c} \sum_{k=1}^{n e r i o d} T Z Q_{o, p, j, k} \times\left(c t 1_{j}+c t 2_{j}\right) \times v c_{j}\right] \\
+\left[\left(\sum_{j=1}^{n c} \sum_{k=1}^{p e r i o d} d_{j, k}-\sum_{o=1}^{n z} \sum_{p=1}^{n z} \sum_{j=1}^{n c} \sum_{k=1}^{p e r i o d} T Z Q_{o, p, j, k}\right) \times c t 3_{j} \times v c_{j}\right]
\end{gathered}
$$

The objective function includes members of project costs that are initial cost of molds $(T M)$, cost of mold setting or mold changeover $(T S p M)$, production operation cost of the factory $(T S e M)$, storage cost of adopted sites $(I C)$, and transportation cost of ordered trucks $(T C)$. Equations (4.2)-(4.6) represent calculation of each cost respectively.

\section{- Constraints:}

(1) Production stage:

$$
\begin{gathered}
\forall i \quad b i g M \times U M \geq \sum_{j=0}^{n c} \sum_{k=1}^{\text {period }} \operatorname{Mold}_{i, j, k} \\
\forall i, j, k \quad \operatorname{Mold}_{i, j, k} \leq m a_{i, j} \\
\forall i, j, k \quad \text { Mold }_{i, j, k} \leq 1 \\
\forall i, j, k \in 1 . . \text { period }-1 \quad S C M_{i, k} \geq \text { Mold }_{i, j, k+1}-\operatorname{Mold}_{i, j, k}
\end{gathered}
$$




$$
\begin{gathered}
\forall i \quad S C M_{i, 0}=\sum_{j=1}^{n c} \operatorname{Mold}_{i, j, 1} \\
\forall k \quad \sum_{i=1}^{n m} \sum_{j=1}^{n c} \operatorname{Mold}_{i, j, k} \times v c_{j} \leq l c \\
\forall k \quad p s l=\sum_{i=1}^{n m} \sum_{j=1}^{n c} \operatorname{Mold}_{i, j, k} \times s m_{i} \\
\forall j, k \quad \sum_{i=1}^{n m} \operatorname{Mold}_{i, j, k}=P C_{j, k}
\end{gathered}
$$

Issues in production stage are modeled in Eqs. (4.7)-(4.14). Equations (4.7)-(4.9) are related to molds. First, molds can not produce components unless they are adopted. Next, molds can produce components only if they have the ability to produce the component types the components belong to. Finally, the daily productivity of each mold is one component. If the first use of molds producing a component or a mold changeover behavior occurs, the variable $S C M_{i, k}$ identifies the situation by Eq. (4.10) and (4.11). Two limitations of the factory restrain daily mold productivity: limitation of daily supplied concrete and limitation of factory production space, Eq. (4.12) and (4.13). Equation (4.14) calculates daily produced components for inventory. The variable $P C_{j, k}$ is the bridge between the production stage and the storage stage.

(2) Storage stage

$$
\begin{gathered}
\forall o, k \quad \sum_{m=1}^{n i} Z I S_{o, m, k}+\sum_{n=1}^{n e} Z E S_{o, n, k} \leq 1 \\
\forall j, k \quad \sum_{o=1}^{n z} P C Z_{o, j, k}=P C_{j, k} \\
\forall o, j, k \quad \sum_{m=1}^{n i} B i g M \times Z I S_{o, m, k} \geq P C Z_{o, j, k} \\
\forall o, j, k \quad \sum_{m=1}^{n i} B i g M \times Z I S_{o, m, k}+\sum_{n=1}^{n e} B i g M \times Z E S_{o, n, k} \geq I Z_{o, j, k} \\
\forall m, k \quad b i g M \times U I_{m, k} \geq+\sum_{o=1}^{n z} Z I S_{o, m, k}
\end{gathered}
$$




$$
\begin{aligned}
& \forall o, m, k \in 2 \text {..period } \quad Z I S_{o, m, k} \geq Z I S_{o, m, k-1} \\
& \forall m, k \quad i s l_{m} \geq \sum_{o=1}^{n z} Z I S_{o, m, k} \times s z_{o} \\
& \forall n, k \quad \text { big } M \times U E_{n, k} \geq+\sum_{o=1}^{n z} Z E S_{o, n, k} \\
& \forall o, n, k \in 2 . . p e r i o d \quad Z E S_{o, n, k} \geq Z E S_{o, n, k-1} \\
& \forall n, k \quad e s l_{n} \geq \sum_{o=1}^{n z} Z E S_{o, n, k} \times s z_{o} \\
& \forall o, j \quad I Z_{o, j, 0}=i i z_{o, j} \\
& \forall o, j \quad \sum_{m=1}^{n i} b i g M \times Z I S_{o, m, p e r i o d} \geq I Z_{o, j, p e r i o d} \\
& \forall o, j, k \quad I Z_{o, j, k}=I Z_{o, j, k-1}+P C Z_{o, j, k}+\sum_{p=1}^{n z} T Z Q_{o, p, j, k} \\
& -\sum_{p=1}^{n z} T Z Q_{p, o, j, k}-T W Q_{o, j, k} \\
& \forall o, j, k \quad I Z_{o, j, k} \leq i l z_{o, j}
\end{aligned}
$$

Component zoning and zone locating with inventory issues are formed as Eqs. (4.15)(4.28). Equation (15) explicates that each zone can be located in an internal or external site when it is adopted. If zones are located in an internal site, they can receive the daily supplied components $\left(P C_{j, k}\right)$ from the production stage directly as presented as Eqs. (4.16) and (4.17). Equation (4.18) shows that no inventory is allowed if a zone is not adopted. Equations (4.19)-(4.21) and Eqs. (4.22)-(4.24) represent zone locating for internal sites and external sites respectively. Once a zone is located whether an internal or external site, the site is utilized or rented, and the site must stay utilized or rented till the end of the project. Each site can contain several zones, but space limitation is concerned. Equation (4.25) demonstrates that all zones may have initial inventory at the beginning of the project, but Eq. (4.26) states that only zones located in internal sites can remain inventory at the end 
of the project. Components are stored in zones progressively. Equation (4.27) calculates daily inventory of each zone, and maximum inventory is restrained as Eq. (4.28).

(3) Transportation stage

$$
\begin{aligned}
& \forall o, j, k \quad T Z Q_{o, o, j, k}=0 \\
& \forall o, k \quad \sum_{m=1}^{n i} \operatorname{big} M \times Z I S_{o, m, k} \geq \sum_{p=1}^{n z} \sum_{j=1}^{n c} T Z Q_{o, p, j, k} \\
& \forall p, k \quad \sum_{n=1}^{n e} b i g M \times Z E S_{o, n, k} \geq \sum_{p=1}^{n z} \sum_{j=1}^{n c} T Z Q_{o, p, j, k} \\
& \forall k \quad b i g M \times O T_{k} \geq \sum_{o=1}^{n z} \sum_{p=1}^{n z} \sum_{j=1}^{n c} T Z Q_{o, p, j, k}+\sum_{o=1}^{n z} \sum_{j=1}^{n c} T W Q_{o, j, k} \\
& \forall k \in 1 . . p e r i o d-1 \quad \text { qot } \times O T_{k} \leq \sum_{o=1}^{n z} \sum_{p=1}^{n z} \sum_{j=1}^{n c} T Z Q_{o, p, j, k} \times v c_{j} \\
& +\sum_{o=1}^{n z} \sum_{j=1}^{n c} T W Q_{o, j, k} \times v c_{j} \\
& \forall o, j \quad M I S_{o, j, 1}=P C Z_{o, j, 1} \\
& \forall j, k \in 2 . . p e r i o d \quad M I S_{o, j, k}=P C Z_{o, j, k}+P C Z_{o, j, k-1} \\
& \forall j, k \quad M I S_{o, j, k} \leq \sum_{o=1}^{n z} I Z_{o, j, k}
\end{aligned}
$$

Transportation issues are structured by Eqs. (4.29)-(4.36). Unnecessary transportation is not allowed. Equation (4.29) eliminates transportation within a zone. Transportation between zones is applied instead of transportation between sites. Eqs. (4.30) and (4.31) restrain transportation between zones such that zones in internal sites can only move out components, and those in external sites can only receive components from zones in internal sites. The issue of truck orders is illustrated as Eqs. (4.32) and (4.33). Finally, Eqs. (4.34)-(4.36) represent quantity of components that are not allowed to be transported due to incomplete curing.

(4) Installation stage (work site inventory)

$$
\forall j \quad I W_{j, 0}=i i w_{j}
$$




$$
\begin{gathered}
\forall j, k \quad I W_{j, k}=I W_{j, k-1}+\sum_{o=1}^{n z} T W Q_{o, j, k}-d_{j, k} \\
\forall j, k \quad I W_{j, k}=i l w_{k} \\
\forall j \quad I W_{j, \text { period }}=0
\end{gathered}
$$

Equations (4.37)-(4.40) describe component inventory of the work site. The work site can have initial inventory. Additionally, the daily requirement of component installation must be satisfied. The limitation of inventory is concerned. Finally, no inventory is allowed at the end of the project.

\subsection{Searching strategy and optimization tool}

The proposed model presents a Mix-IP problem. It can be performed and solved with mathematical programming tool or software such as LINDO. However, such a model can contain large searching domain and need computational effort for a solution. The group concepts also lead an effective way on solution searching.

Molds and zones which present ways to group components are key variables to determine the precast project plan. Component requirements must be firstly satisfied by using molds and scheduling what components and when they are produced. Therefore, determining variables Mold $_{i, j, k}$ can rapidly reduce infeasible variable domain. Similarly, $Z I S_{o, m, k}$ and $Z E S_{o, n, k}$ play the core to determine how components are stored and transported. The searching strategy, branch-and-bound priority, are primarily advised and shown as Figure 2. The Constraint Programming, which can also refer to Chan and $\mathrm{Hu}$ [4], is adopted since it provides the flexibility on setting branch-and-bound details for the searching strategy. Furthermore, ILOG OPL which contains Constraint Programming is the adopted optimization tool in this study.

\subsection{Required molds and zones}

As mentioned before, molds can be grouped into mold types if they have the same ability to produce corresponding grouped component types. Although concepts of mold type are not involved in the proposed model, they are significant while practicing the model. There are always questions that planners do not often recognize as to which mold type and how many molds are beneficial to produce components. A similar situation occurs in choosing appropriate zones to store components. Concepts of mold type and zone type aim at these issues.

To represent a mold type, planners can appoint the parameter $m a_{i, j}$ that mold index $i$ in a range has the same ability to produce components belonging to each component type $j$. Additionally, there are similar settings of parameters $i c m_{i}$ and $s m_{i}$ with the same range for initial cost and required space issues. Therefore, molds in the range are identical. Equivalently, The parameters $s z_{o}$ and $i l z_{o, j}$ play similar roles to zones. Zones in a range of index $o$ can be appointed to be identical in space requirements and limitation of component inventory for a zone type.

A recursive procedure is proposed to determine required molds and zones. First of all, each mold type contains two molds in consideration. After optimization of solving the 
Table 1: Parameter symbols

\begin{tabular}{|c|c|c|c|}
\hline Symbol & Explanation & Symbol & Explanation \\
\hline$n m$ & $\begin{array}{l}\text { Number of considered } \\
\text { molds }\end{array}$ & $i$ & Index of molds \\
\hline$n c$ & $\begin{array}{l}\text { Number of component } \\
\text { types }\end{array}$ & $j$ & $\begin{array}{l}\text { Index of component } \\
\text { types }\end{array}$ \\
\hline period & Project period & $k$ & Index of workdays \\
\hline$n i$ & Number of internal sites & $m$ & Index of internal sites \\
\hline$n e$ & Number of external sites & $n$ & Index of external sites \\
\hline$n z$ & $\begin{array}{l}\text { Number of considered } \\
\text { zones }\end{array}$ & $o, p$ & Index of zones \\
\hline$l c$ & $\begin{array}{l}\text { Daily limitation of sup- } \\
\text { plied concrete }\left(\mathrm{m}^{3}\right)\end{array}$ & $i c$ & $\begin{array}{l}\text { Daily cost of internal site } \\
\mathrm{m} \text { if it is utilized. (\$) }\end{array}$ \\
\hline$\overline{d_{j, k}}$ & $\begin{array}{l}\text { Required components of } \\
\text { type } j \text { at day } k\end{array}$ & $e c$ & $\begin{array}{l}\text { Daily cost of external site } \\
n \text { if it is rented. }(\$)\end{array}$ \\
\hline$s m_{i}$ & $\begin{array}{l}\text { Required work space of } \\
\text { mold } i .\left(m^{2}\right)\end{array}$ & ct 1 & $\begin{array}{l}\text { Component transporta- } \\
\text { tion from factory to } \\
\text { zone } j \text { in external sites. } \\
\left(\$ / \mathrm{m}^{3}\right)\end{array}$ \\
\hline$v c_{j}$ & $\begin{array}{l}\text { Volume of component } \\
\text { type } j\left(m^{3}\right)\end{array}$ & ct2 & $\begin{array}{l}\text { Component transporta- } \\
\text { tion from zone } j \text { in exter- } \\
\text { nal sites to the work site. } \\
\left(\$ / \mathrm{m}^{3}\right)\end{array}$ \\
\hline$p o c$ & $\begin{array}{l}\text { Production operation } \\
\text { cost }\left(\$ / m^{2} / \text { day }\right)\end{array}$ & $c t 3$ & $\begin{array}{l}\text { Component transporta- } \\
\text { tion from factory to the } \\
\text { work site }\left(\$ / \mathrm{m}^{3}\right)\end{array}$ \\
\hline$p s l$ & $\begin{array}{l}\text { Production space limita- } \\
\text { tion }\left(\mathrm{m}^{2}\right)\end{array}$ & $s z_{o}$ & $\begin{array}{l}\text { Required space of zone } o \\
\left(\mathrm{~m}^{3}\right)\end{array}$ \\
\hline $\mathrm{icm}_{i}$ & Initial cost of mold $i(\$)$ & $i s l_{m}$ & $\begin{array}{l}\text { Space limitation of inter- } \\
\text { nal site } m\left(m^{3}\right)\end{array}$ \\
\hline$m a_{i, j}$ & $\begin{array}{l}\text { Ability of mold } i \text { to pro- } \\
\text { duce component type } j\end{array}$ & $e s l_{n}$ & $\begin{array}{l}\text { Space limitation of exter- } \\
\text { nal site } n\left(\mathrm{~m}^{3}\right)\end{array}$ \\
\hline $\mathrm{scm}$ & $\begin{array}{l}\text { Setting or changeover } \\
\text { cost of molds }(\$)\end{array}$ & $i i z_{o, j}$ & $\begin{array}{l}\text { Initial inventory of com- } \\
\text { ponent type } j \text { in zone } o\end{array}$ \\
\hline$i l w_{j}$ & $\begin{array}{l}\text { Daily storage limitation } \\
\text { of component type } j \text { in } \\
\text { the work site. }\end{array}$ & $i l z_{o, j}$ & $\begin{array}{l}\text { Quantity limitation of } \\
\text { zone } o \text { to store compo- } \\
\text { nent type } j\end{array}$ \\
\hline qot & $\begin{array}{l}\text { Minimal component } \\
\text { quantity (weight) of } \\
\text { ordering trucks (ton) }\end{array}$ & $i i w_{j}$ & $\begin{array}{l}\text { Initial inventory of com- } \\
\text { ponent type } j \text { in work } \\
\text { site }\end{array}$ \\
\hline$\overline{b i g M}$ & A very big number & & \\
\hline
\end{tabular}


Table 2: Variable symbols

\begin{tabular}{|c|c|c|c|}
\hline Symbol & Explanation & Symbol & Explanation \\
\hline$T M$ & Total initial cost of molds & TSeM & $\begin{array}{l}\text { Total cost of setting or } \\
\text { changeover of molds }\end{array}$ \\
\hline$T S p M$ & Total production cost & $I C$ & Total storage cost \\
\hline$T C$ & Total transportation cost & & \\
\hline $\bar{U} I_{m, k}$ & $\begin{array}{l}\text { Utilization of internal } \\
\text { site } m \text { on day } k(0,1)\end{array}$ & $U E_{n, k}$ & $\begin{array}{l}\text { Adoption of external site } \\
n \text { on day } k(0,1)\end{array}$ \\
\hline Mold $_{i, j, k}$ & $\begin{array}{l}\text { Decision of mold } i \text { pro- } \\
\text { ducing component type } j \\
\text { on day } k(0,1)\end{array}$ & $T Z Q_{o, p, j, k}$ & $\begin{array}{l}\text { Quantity of transported } \\
\text { component } j \text { from zone } o \\
\text { to zone } p \text { on day } k \text { (Inte- } \\
\text { ger) }\end{array}$ \\
\hline$U M_{i}$ & Adoption of mold $i(0,1)$ & $Z I S_{o, m, k}$ & $\begin{array}{l}\text { Judgment of zone } o \text { lo- } \\
\text { cated in internal site } m \\
\text { on day } k(0,1)\end{array}$ \\
\hline$S C M_{i, k}$ & $\begin{array}{l}\text { Judgment of setting or } \\
\text { changeover of mold } i \text { on } \\
\text { day } k(0,1)\end{array}$ & $Z E S_{o, n, k}$ & $\begin{array}{l}\text { Judgment of zone } o \text { lo- } \\
\text { cated in external site } n \\
\text { on day } k(0,1)\end{array}$ \\
\hline$P C_{j, k}$ & $\begin{array}{l}\text { Produced components of } \\
\text { component type } j \text { on day } \\
k \text { (Integer) }\end{array}$ & $P C Z_{o, j, k}$ & $\begin{array}{l}\text { Quantity of produced } \\
\text { component type } j \text { in } \\
\text { zone } o \text { on day } k \text { (Integer) }\end{array}$ \\
\hline$O T_{k}$ & $\begin{array}{l}\text { Decision of ordering } \\
\text { trucks on day } k(0,1)\end{array}$ & $I Z_{o, j, k}$ & $\begin{array}{l}\text { Inventory of component } j \\
\text { in zone } o \text { on day } k \text { (Inte- } \\
\text { ger) }\end{array}$ \\
\hline$\overline{M I S_{o, j, k}}$ & $\begin{array}{l}\text { Quantity of component } \\
\text { type } j \text { in zone } o \text { on day } k \\
\text { for strength issues. (In- } \\
\text { teger) }\end{array}$ & $I W_{j, k}$ & $\begin{array}{l}\text { Inventory of component } \\
\text { in the work site on day } k \\
\text { (Integer) }\end{array}$ \\
\hline$P S_{k}$ & $\begin{array}{l}\text { Judgments for molds' } \\
\text { changeover }(0,1)\end{array}$ & $T W Q_{o, j, k}$ & $\begin{array}{l}\text { Quantity of trans- } \\
\text { portable component type } \\
j \text { on day } k \text { for strength } \\
\text { issues. (Integer) }\end{array}$ \\
\hline
\end{tabular}




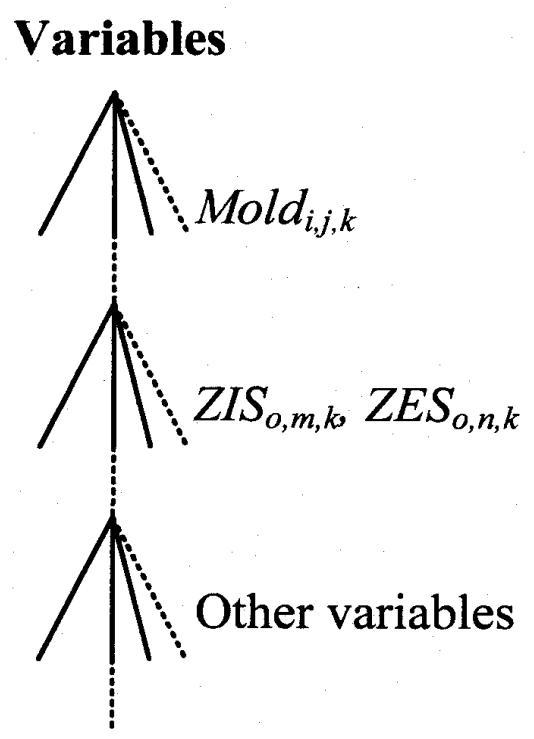

Figure 2: Searching strategy

proposed model based on temporary project parameters, the appropriate molds are picked out. If variables of $U M_{i}$ of the optimal solution in the range for a mold type indicate that one surplus exists or both molds are not adopted, the suitability of the mold type is temporarily assured. In case of one surplus mold, one mold is enough for the production plan; in the other, the mold type is not suitable. Moreover, if both molds are adopted, there is a possibility that an additional mold of the mold type can offer a better solution for the production plan. An extra optimization starts with an additional mold. After the extra optimization, suitability of each mold type can be checked afresh. Such a procedure repeats till at least one surplus exists in each mold type in an optimal solution. The suitability of all mold types can be assured, and the production plan is made. As in the example of molds, zones can be determined in a similar procedure. The variables $Z I S_{o, m, k}$ and $Z E S_{o, n, k}$ play similar roles for zone types in the storage plan. The overall process of the recursive procedure is shown as Figure 3.

Another reason for the recursive procedure and group concepts is to assure the efficiency of the proposed model. The four indexes, $i$ for molds; $j$ for component types; $k$ for workdays; $o$ for zones, dominate complexity of the model for a project. Although precast projects can be simplified by standardized components, an immense model can be caused by haphazard molds and zones. Massive effort to solve the immense model may be needed and also meaningless. Considering the recursive procedure and group concepts, required molds and zones can be confirmed step by step respectively. In each step, few variables of molds and zones are retained, so that two variables for each mold type and zone type are recommended herein. If an additional mold (or zone) is considered, one of the adopted molds (or zones) can directly be appointed as necessary in the next step. Therefore, two variables are kept for each mold type (zone type) in each step of the recursive procedure to check demand for the additional mold (zone). Thus, meaningless efforts can be prevented. Once the final solution is achieved and required molds and zones are confirmed, a plan of the precast project is advised. 

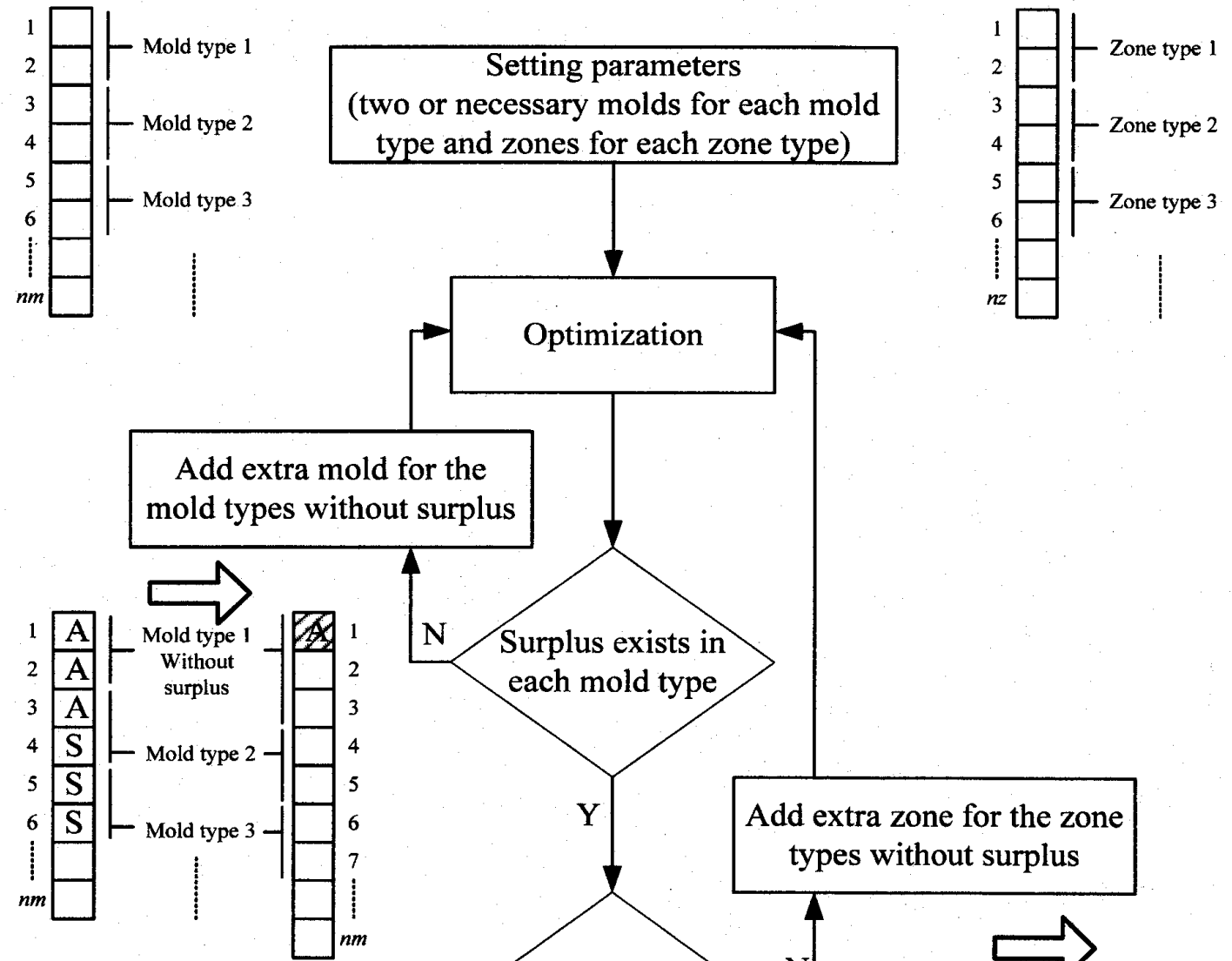

A considered mold or zone.

A The mold, or zone, is adopted.

$\mathrm{S}$ The mold, or zone, is not adopted.

24. Adopted mold, or zone, is kept in the next step.

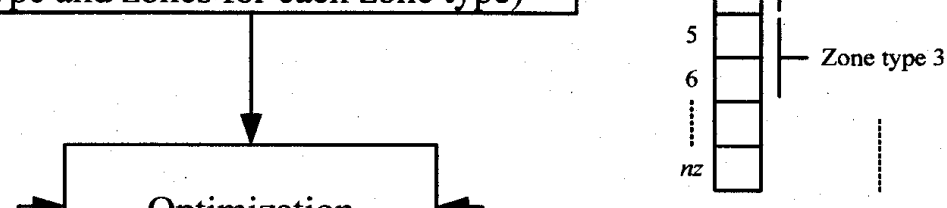

Figure 3: Recursive procedure 
Table 3: Information of example project

\begin{tabular}{|c|c|c|c|}
\hline $\begin{array}{l}\text { Parameters } \\
\text { period } \\
\text { nc } \\
n i\end{array}$ & $\begin{array}{cc}\text { Value } & \text { Parameters } \\
10 \text { (days) } & n e \\
3 \text { (types) } & l c \\
2 \text { (units) } & p o c\end{array}$ & $\begin{array}{c}\text { Parameters } \\
\text { psl } \\
\text { qot } \\
\text { scm }\end{array}$ & $\begin{array}{cc}\text { Value } & \text { Parameters } \\
100\left(\mathrm{~m}^{2}\right) & c t 1_{j} \\
18(\text { tons }) & c t 2_{j} \\
100(\$) & c t 3_{j}\end{array}$ \\
\hline$n m$ & $\begin{array}{l}\text { Not determined } \\
(3 \text { mold types considered })\end{array}$ & $n z$ & $\begin{array}{l}\text { Not determined } \\
\text { (4 zone types considered) }\end{array}$ \\
\hline $\begin{array}{c}\text { Parameters } \\
s m_{i} \\
\end{array}$ & $\begin{array}{l}\text { Value (mold }[1,2]) \\
{[8,12,14]\left(m^{2}\right)}\end{array}$ & $\begin{array}{c}\text { Parameters } \\
i c m_{i} \\
\end{array}$ & $\begin{array}{l}\text { Value (mold }[1,2]) \\
{[100000,130000,150000](\$)}\end{array}$ \\
\hline $\begin{array}{c}\text { Parameters } \\
v c_{j} \\
i l w_{j} \\
\end{array}$ & $\begin{array}{l}\text { Value (component type }[1,2,3]) \\
{[5,4,2]\left(\mathrm{m}^{3}\right)} \\
{[5,5,5] \text { (units) }}\end{array}$ & $\begin{array}{c}\text { Parameters } \\
i i w_{j}\end{array}$ & $\begin{array}{l}\text { Value (component type }[1,2,3]) \\
{[0,0,0] \text { (units) }}\end{array}$ \\
\hline $\begin{array}{c}\text { Parameters } \\
i c_{m}\end{array}$ & $\begin{array}{l}\text { Value (internal site }[1,2]) \\
{[3000,3500](\$)}\end{array}$ & $\begin{array}{c}\text { Parameters } \\
i s l_{m} \\
\end{array}$ & $\begin{array}{l}\text { Value (internal site }[1,2]) \\
{[30,35]\left(m^{2}\right)}\end{array}$ \\
\hline $\begin{array}{c}\text { Parameters } \\
e c_{n} \\
\end{array}$ & $\begin{array}{l}\text { Value (external site }[1,2,3]) \\
{[6000,3600,2400](\$)}\end{array}$ & $\begin{array}{c}\text { Parameters } \\
e s l_{n}\end{array}$ & $\begin{array}{l}\text { Value (external site }[1,2,3]) \\
{[50,30,20]\left(\mathrm{m}^{2}\right)}\end{array}$ \\
\hline $\begin{array}{c}\text { Parameters } \\
s z_{o} \\
\end{array}$ & $\begin{array}{l}\text { Value (zone }[1,2]) \\
{[20,22,18,17](\mathrm{m} 2)} \\
\end{array}$ & & \\
\hline$\overline{\text { Parameters }}$ & $\begin{array}{l}\text { Value (units) } \\
\text { (workday }[1,2, . ., 10] \text { ) }\end{array}$ & Parameters & $\begin{array}{l}\text { Value (can produce }=1) \\
\text { (component type }[1,2,3])\end{array}$ \\
\hline$d_{j, k}$ & $\begin{array}{l}\text { Component type } 1[0,0,0,0,0,0,0,0,10,0] \\
\text { Component type } 2[0,0,0,0,0,0,0,0,10,0] \\
\text { Component type } 3[0,0,0,0,0,0,0,0,0,20]\end{array}$ & $m a_{i, j}$ & $\begin{array}{l}\text { Mold type } 1[0,0,1] \\
\text { Mold type } 2[1,1,0] \\
\text { Mold type } 3[1,1,1] \\
\end{array}$ \\
\hline Parameters & $\begin{array}{l}\text { Value (units) } \\
\text { (component type }[1,2,3] \text { ) }\end{array}$ & Parameters & $\begin{array}{l}\text { Value (units) } \\
\text { (component type }[1,2,3] \text { ) }\end{array}$ \\
\hline$i i z_{o, j}$ & $\begin{array}{l}\text { Zone type } 1[0,0,0] \\
\text { Zone type } 2[0,0,0] \\
\text { Zone type } 3[0,0,0] \\
\text { Zone type } 4[0,0,0]\end{array}$ & $i l z_{o, j}$ & $\begin{array}{l}\text { Zone type } 1[3,3,3] \\
\text { Zone type } 2[0,5,3] \\
\text { Zone type } 3[2,0,5] \\
\text { Zone type } 4[3,6,0]\end{array}$ \\
\hline
\end{tabular}

\section{Example Experiment}

An example of a precast project with component information and installation information is assumed. In order to represent and explicate project information and results transparently, the example project contains 3 component types, 3 mold types, 4 zone types, 2 internal sites, and 3 external sites under a 10-day contract. The detailed information is shown as Table 3.

At the beginning of solving the example model, two molds and zones are temporarily appointed for each mold type and each zone type respectively. To ensure required molds, three steps of the recursive procedure are performed. The required molds are two molds of mold type 1 ; none of mold type 2 ; three molds of mold type 3 . After the required molds are confirmed, required zones are assured in the second step of the continued recursive procedure, they are none of zone type 1 ; none of zone type 2; three zones of zone type 3; one zone of zone type 4 . The final optimal solution of the example project is shown as Figure 4. The average solving time of the example project for all steps of the recursive procedure is about 20 minutes. The calculator with $1.8 \mathrm{GHz}-1.8 \mathrm{GHz}$ Dual CPU and $2 \mathrm{~GB}$ RAM.

The optimal solution is achieved with total project cost $\$ 996,200$ where $T M$ is $\$ 650,000$; $T S p M$ is $\$ 240,000 ; T S e M$ is $\$ 900 ; I C$ is $\$ 58,400 ; T C$ is $\$ 46,900$.

In the production stage, five molds that were confirmed in the recursive procedure are 


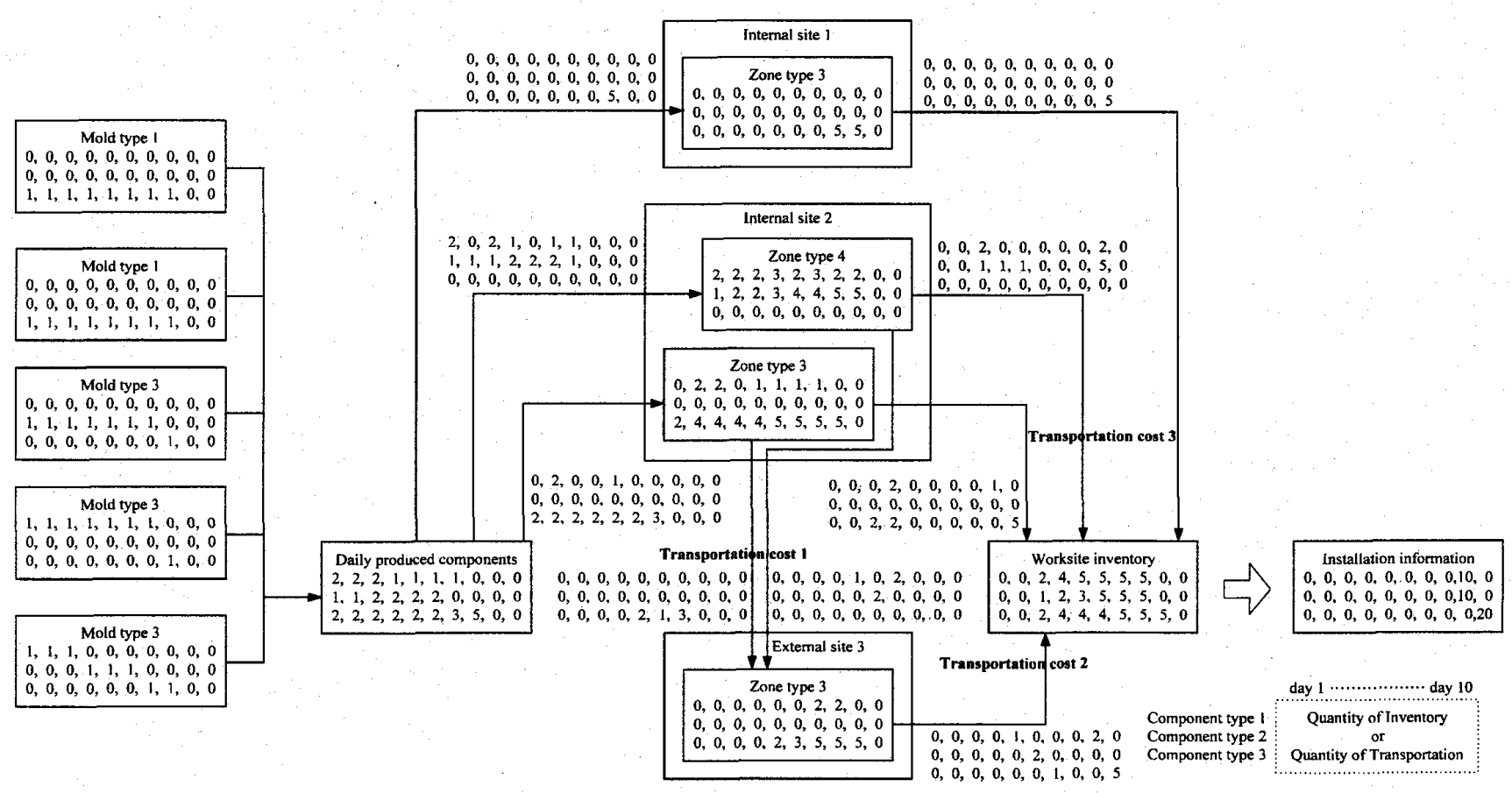

Figure 4: Optimal solution of example project

planned to produce required components. Total mold initial cost is $\$ 650,000$, and setting cost of mold is $\$ 500$. Four changeovers are minimized and identified in molds of mold type 3. Molds do not produce components on day 9 and day 10 because of curing issues. No mold idles from day 1 to day 8 , and no overproduction occurs. Resources are sufficient, so that daily supplied concrete and production space do not restrain production plan. The production plan is shown as the left part of molds in Figure 4.

In storage stage, four zones confirmed in the recursive procedure and three sites are adopted to store required components. Three zones of zone type 3 are adopted to cater to demand for component types 1 and 3, and one zone of zone type 4 is adopted to cater to demand for component types 1 and 2. Moreover, external site 3 is adopted because of the insufficient space in internal sites. There is an interesting investigation. External site 3 was adopted prior to internal site 2. Although internal site 2 has lower average site usage cost that is $\$ 100$ per $m^{2}\left(\$ 3500 / 35 m^{2}\right)$ than external site 3 that is $\$ 120$ per $m^{2}(\$ 2400 / 20$ $\mathrm{m}^{2}$ ), and additional transportation is required when the external site is adopted, external site 3 is still economical considering overall site cost. Thus, the appropriate zones and sites are recognized through the proposed model. Not only are the required zones assured in the recursive procedure, but the appropriate sites are selected through optimization. Another subject for inquiry is that the inventory of some adopted zones is not totally utilized. For example, the only adopted zone of zone type 4 never reaches its maximum inventory. Although zone type 4 is the best option in the current storage plan, the optimal solution may be refined if more options of zone types are offered. Thus, various zone types are still encouraged.

In the transportation stage, the transportation plan is successfully created. Unnecessary transportation is avoided. For example, there is no transportation whether from zones in external sites to those in internal sites or from work site to zones. Furthermore, the truck order issue has also reduced transportation times to accommodate the practical situation. To obey daily minimal transportation, a significant transportation investigation occurrs. A 
component of component type 1 is transported from zone type 4 in internal site 1 to zone type 3 in external site 3; simultaneously, it is continually transported to the work site on day 5. The daily minimal transportation can be satisfied since the component is transported twice. However, this transportation may be not reasonable in practice. Therefore, some specific constraints of component transportation may be needed, or planners can convince the truck supplier to transport the component to the work site directly without additional transportation cost. Moreover, the curing issue has further influence on the production plan as mentioned. In fact, all parameters in the proposed model can influence the overall project. Various dilemmas can be investigated. Planners must meditate on necessary considerations as parameters to create a precast project plan.

The proposed model is only represented by an example experiment to conduct a guide of precast project planning. Although group concepts can structure a framework, grouping details can be case by case for different precast factories and different projects. Setting molds and zones is fundamental to present real situations. Planners are encouraged to survey on setting molds and zones based on their own circumstance. For example, setting molds relate to techniques adopted in factory. Setting zones refer to experts or performers on component storage. When only rules and parameters of molds and zones are further identified, the proposed model is then practical. Nevertheless, the proposed model is applicable and flexible for precast projects based on group ideas.

\section{Conclusion}

To offer a solution of precast project planning from the factory perspective in the domain of combining production stage, storage stage, and transportation stage, this study adopts several group concepts and proposes a mathematical model. To simplify the overall precast project process, components are standardized (or grouped) into component types; molds can produce components within grouped component types; produced components are grouped into zones to present component storage; zones are allocated (or grouped) into sites to store components. To determine required molds and zones and to avoid immense models, molds and zones are also grouped into mold types and zone types, and a recursive procedure is proposed. Finally, an example project demonstrates the feasibility of the proposed model. The example is successfully solved to offer a solution under overall consideration of precast projects.

The proposed model is based on the group concepts. It can be modified to cater to any individual project environment. Furthermore, it can be adopted partially. For instance, the production plan and the storage plan are connected by the variable $P C_{j, k}$. If the parameter $d_{j, k}$ is used instead of the variable $P C_{j, k}$, the production plan of a precast project can be independently created by related constraints and members of objective functions with minor modifications. Contrarily, a storage plan can be created similarly by replacing the variable $P C_{j, k}$ with a known component supply if possible. However, storage stage and transportation stage must be considered together to complete a problem since these two stages are the two sides of one coin. Nevertheless, the group concepts are fundamental to plan a precast project.

\section{Acknowledgements}

The authors would like to thank Ruentex Group which authorized Taiwan Construction Research Institute to help proceed and complete this study smoothly. In addition, the National Science Council of the Republic of China, Taiwan, for financially support to complete 
this research under Contract No. NSC95-2221-E-224-071.

\section{References}

[1] Acheson and Glover: Precast storage system, http://acheson-glover.gundan. unite.net/commercial/precast.

[2] M. Avriel, M. Penn, N. Shpirer, and S. Witteboon: Stowage planning for container ships to reduce the number of shifts. Annals of Operations Research, 76(1) (1998) $55-71$.

[3] W.T. Chan and H. Hu: Production scheduling for precast plants using a flow shop sequencing model. Journal of Computing in Civil Engineering, 16(3) (2002), 165-174.

[4] W.T. Chan and H. Hu: Constraint programming approach to precast production scheduling. Journal of Construction Engineering and Management, 128(6) (2002), $513-521$.

[5] W.T. Chan and Z. Zeng: Coordinated production scheduling of prefabricated building components. Proceedings of Construction Research Congress - Wind of Change: Integration and Innovation (2003), doi 10.1061/40671(2003)106.

[6] W.T. Chan and Z. Zeng: Rescheduling precast production with multiobjective optimization. Proceedings of the 2005.ASCE International Conference on Computing in Civil Engineering (2005), doi 10.1061/40794(179)166.

[7] W.H. Chan and M. Lu: Logistics and operations simulation in precast viaduct construction: case study. Proceedings of the 2005 ASCE International Conference on Computing in Civil Engineering (2005), doi 10.1061/40794(179)130.

[8] S. Cetinkaya, F. Mutlu, and C.Y. Lee: A comparison of outbound dispatch policies for integrated inventory and transportation decisions. European Journal of Operational Research, 171(3) (2006), 1094-1112.

[9] S.S. Leu and S.T. Hwang: GA-based resource-constrained flow-shop scheduling model for mixed precast production. Automation in Construction, 11(4) (2002) 439-452.

[10] M.B. Sadiq, T.L. Landers, and G.D. Taylor: An assignment algorithm for dynamic picking systems. IIE Transactionsh, 28 (1996) 607-616.

[11] K.C. Shih, S.S. Liu, and C.N. Huang: Precast storage and transportation planning via component zoning optimization. Robotics and Automation in Construction, (2008) $159-174$.

[12] I.F.A. Vis and R. Koster: Transshipment of containers at a container terminal: An overview. European Journal of Operational Research, 147(1) (2003) 1-16.

Kuo-Chuan Shih

PhD Researcher

AI-Econ Research Center

College of Social Sciences

National Chengchi University

No. 64, Sec. 2, Chih-Nan Road

Taipei, Taiwan, 116, ROC,

E-mail: g9310816@yuntech.edu.tw 